\title{
SPATIO-TEMPORAL CHANGES IN WHEAT CROP CULTIVATION IN INDIA
}

\author{
P. Krishnan ${ }^{1, *}$, Pramila Aggarwal ${ }^{1}$, Nilimesh Mridha ${ }^{1}$, Vaishangi Bajpai ${ }^{1}$ \\ ${ }^{1}$ Division of Agricultural Physics, \\ Indian Agricultural Research Institute, \\ New Delhi 110012
}

Commission III, WG III/10

KEY WORDS: Wheat, GIS, area, production, yield, Emerging hot and cold spot analysis, spatial and temporal changes

\begin{abstract}
:
This study was conducted to understand the changes in spatiotemporal characteristics of wheat crop production including the changes in area and yield. We employed the emerging hot and cold spot analysis along with space time cube and space-time cluster density analysis to study the spatial changes in wheat crop production, area and yield, and understand the changes in spatiotemporal features. We made a comprehensive analysis of the changes in wheat crop production, area and yield on pan India basis for the period from 1999 to 2015. The major findings were: (a) During the study period significant increase in wheat yield occurred within the North Indian states of Punjab and Haryana and intensifying hot spots appeared within the Indo-Gangetic plains. (b) The Analysis of the area under wheat cultivation showed a persistent hot spot in the Northern states of Uttarakhand and Uttar Pradesh, Punjab and Haryana, with new hot spots observed in the regions of Central India during the years 2014 and 2015. (d) The analysis of the wheat crop production showed significant new cold spots in Rajasthan and Gujarat, with intensifying hotspots emanating into the lower delta regions of Ganges. Present study also revealed the potential of GIS based data models when related with additional background information, to segregate the most significant clusters of changes (increase / decrease) happening over active wheat crop cultivation. We expect the results from this study to help in increasing the wheat crop yield and production in the future.
\end{abstract}

\section{INTRODUCTION}

Considerable changes have been made in wheat crop cultivation over the past decades, largely driven by the crop yield enhancement to meet the global demand for food due to the increase in global population (Ramankutty et al. 2008). Food demand is expected to increase anywhere between 59 to $98 \%$ by 2050 (FAO, 2017). Increase in wheat crop cultivation is possible through increasing the crop yields or area under cultivation or both. (Gilliham et al. 2017). Understanding the economic, social and environmental importance of the agro ecosystems and the anthropological ability to enhance crop cultivation by means of better techniques and land use policies, numerous national and international cooperation have been made to increase wheat crop production. Many of the world's largest wheat producing countries have come together to increase the wheat crop production (The International Wheat Yield Partnership (IWYP), 2016), and these international agreements include ambitious goals to enhance wheat productivity, sustainability and quality production all over the world (Wheat Initiative, 2011) similar initiative were made by the Government of India (National Food Security Mission (NFSM), 2014).

Geostatistics uses regionalised variables to describe a phenomena in a geographical distribution (Kang et al., 2018). Data on crop yield, area and production exhibit spatial continuity but are difficult to collect from every location. Today geostatistics are used to explore and describe spatial variation in agricultural data: Heat stress (Teixeira et al., 2013); yield simulations (Priya, S., \& Shibasaki,, 2001); Yield trends (Ray et al., 2013); forest loss (Harris et al., 2017); yield and grain quality (Diacono, et al., 2012); yield potential and yield gap (Chen et al., 2017) and even for disease (Atkinson, P.J., \& Unwin 2002). These data and other products obtained from agricultural crop data have basically transformed the manner in which the global crop growth are observed and monitored. However as availability of data become bigger, more multifaceted and huge, the capability to swiftly reconnoitre and understand patterns of changes with confidence becomes a serious difficulty to efficiently utilize these data in order to apprise, crop management and policy decisions. Analysis by Ray et al. (2013) using 20 years of crop cultivation data from 1989 to 2008, globally covering 13,500 political units, and visibly assessing patterns in the data at numerous temporal and spatial scales swiftly observed to be impossible, but can be possible through the use of combined spatio-temporal analysis using geostatistics. With the increase in the level of analysis, detecting the changes in spatial patterns and temporal changes (trends), only by visual examination become very challenging (Kang et al., 2018). In addition, these visual examinations do not provide a clear guidance of identifying more elusive, still vital, developments in the acceleration or deceleration of wheat cultivation in any region.

The objectives of the present investigation were (i) to develop a scalable methodological approach which gives a quick assessment of the spatial and temporal statistical trends in crop cultivation data and (ii) to assess the spatial and temporal changes in wheat crop area, yield and production in India during the past years using geospatial statistics. We hypothesise that the spatial-temporal changes in wheat cultivation has resulted in new hot and cold spots in wheat cultivation in India. While temporal changes could increase hot spots due to increase in yield with decrease in 
area, potentially due to the stronger positive effect by high yielding varieties and crop management practices. We aim to provide knowledge for improving wheat crop production which will be useful to enhance wheat production to tackle the threats due to increase in population and climate change.

In order to demonstrate our approach, we have used 17 years annual time series wheat crop cultivation data on area, production and yield for India. Recent studies have shown the importance of these three crop data under various scenarios to enhance crop cultivation (Shiferaw et al. 2013; Acharya et al. 2012), however these studies have not identified, geographically, where the administration should emphasise their policy in order to achieve the envisaged crop improvements. An approach that bring about rapid understanding towards countering this problem could help in the formation and implementation of timely and comprehensible strategies on where to concentrate on crop monitoring and production management efforts.

\section{DATA AND METHODOLOGY}

\subsection{Definitions}

Any region or value if it is relatively higher than its surroundings then it is termed as 'hot spot', similarly if it is relatively lower than its surroundings then its termed as "cold spot" (Harris et al. 2017). In agricultural context, identification of location or region of yield improvement based on expert opinion and scenario analyses, is of great concern. In this study, a hot spot is defined as an area that has statistically significant clustering in the spatial pattern of crop improvement in terms of cultivated crop area, production and yield. Thus, hot spots are locations in which the perceived patterns are not possibly due to the outcome of arbitrary procedures or subjective cartographic pattern based conclusions; hotspots actually signify the locations where primary spatial processes are important (Getis and Ord, 1992). This definition is further extended to Emerging Hot Spot Analysis to integrate data pertaining to the temporal dimensions.

In this study, crop improvement is considered as a 'crop augmentation', denoting the enhancement or significant improvement of crop cultivation due to various agricultural factors. Thus crop improvement as considered in this study signifies crop augmentation, i.e. crop yield increase, intensification of crop cultivation or crop production enhancement (Tilman et al. 2011, Monfreda et al. 2008). However, crop yield enhancement dominates the crop improvement dynamics observed within the three components chosen for this analysis, namely area of cultivation, crop production and crop yield.

\subsection{Region of study}

Spatio-temporal changes as Emerging Cold and Hot Spot Analysis could be conducted at a country dimension by utilising one set of homogenous factors throughout the geographic domains. Nevertheless, to be pertinent for land use and planning, all these assessments are probably more valuable when they correlate with the changes happening inside the boundaries of particular domains. Hence this study is conducted pertaining to the Indian sub-continent. India is the second largest producer of wheat in the world. Data on crop production, area and yield are essential parameters to describe the crop performance temporally and spatially, in addition they assume prime importance in the agricultural statistics of a country.

\subsection{Crop cultivation data}

Crop Area: In India cadastral surveys are used to collect information on area under which a crop is cultivated for a particular season. The land statistics and crop area are available as a part of the land records which is maintained by the revenue agencies (denoted as "Land Record State"). This system of land records is followed in all the states of India.

Crop Yield: Yield is one of the most important component of crop production statistics. In India, scientifically designed Crop Cutting Experiments (CCEs) are conducted systematically to obtain the yield estimates of important crops like wheat. From the perspective of crop improvement, the major focus of the General Crop Estimation Survey (GECS) is to obtain impartial and dependable evaluations of average yield. In a selected field the crop cutting experimental plots are of a specified size and shape. The percentage recovery of dry grains or the marketable form of the produce are documented based on the principle of random sampling, harvesting, threshing and recording the harvested produce.

Production: The estimates of crop production are determined by multiplying the area data with the corresponding yield data.

\subsection{Data Analysis}

The data on crop area, production and yield are in general used for planning, policy formulation and implementation by the researchers and administrators. We have taken India as the major study area to test our methodology. India represent an ideal candidate to test our methodology because it is controlled by diverse crop performance dynamics, ranging from large tract of fertile Indo Gangetic plain to dry regions of North-west comprising Rajasthan. Present study is focused at the national scale for the three important crop cultivation parameters (area, yield and production), and also provide the effectiveness of a scalable approach by creating output maps for a single state (Punjab) and for the fertile indo-Gangetic plain.

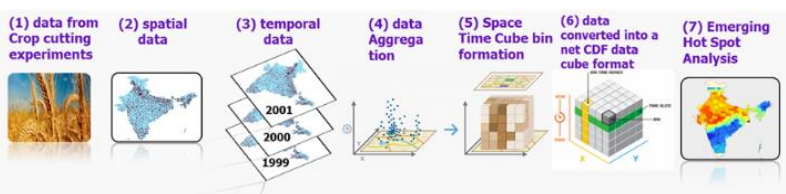

Figure 1. Workflow for data processing and analysis for transforming the crop cutting experiment data (district wise) into an emerging hot spot map (Spatio - temporal analysis)

\subsection{Input data handling}

Workflow of the processing steps used in the present study is given in Figure 1, in a concise form. Input data comprised of crop yearly data on area, production and yield produced by the Directorate of Economics \& Statistics (DES), Government of India. These are delivered as point data at district level. Before running statistical analysis, these data are converted in the form of a netCDF (Network Common Data Form) data cube format by combining crop performance data points in each district into space-time 
'bins' (Figure 1). Each bin value was allocated with the count (number) for change in crop cultivation in that bin for that particular year. In addition to the latitude and longitude coordinates that are stored as space, the netCDF structure stores time (i.e. the year in which the change in crop cultivation was perceived) as an additional dimension. In this study a count of change points to each and every bin for all sites comprising crop in the start (year 1999) is assigned, latter the trend in point counts over time (for each year) is evaluated. Statistical analysis was done by using Environmental Systems Research Institute (ESRI) ArcGIS Emerging Hot and Cold Spot Analysis geo-processing tool and map symbolization was done by ESRI software.

\subsection{Geo- Spatial analysis}

Space-time cube analysis is a 3D geo-visualization technique that maps spatiotemporal data in a cube and is useful for finding spatiotemporal patterns. A $3 \mathrm{D}$ cube is made up of space-time bins with the $\mathrm{x}$ and $\mathrm{y}$ dimensions representing space and the $t$ dimension representing time. Every bin has a fixed position in space $(\mathrm{x}, \mathrm{y})$ and in time (z).

The Emerging Cold and Hot Spot Analysis tool was used to assess spatiotemporal patterns in wheat crop cultivation in India, by combining two numerical statistics methods: (i) the Getis-Ord Gi* statistic (Ord \& Getis, 1995): conducted to detect the site specific and spatial extent of clustering of crop cultivation, in addition (ii) the Mann-Kendall trend test (Mann, 1945; Kendall \& Gibbons, 1990) performed and temporal (timed-based) trends among the data considered for analysis was estimated.

Initially, the Getis-Ord Gi* statistical techniques determines the degree of clustering of high or low data values in a bin (i.e. counts of change in crop cultivation parameters - area, production and yield) compare with its neighbouring bins. Then the summation of all bins is compared proportionally to the sum for a particular bin and its neighbours. Once a bin's sum is not the same as expected, and that the dissimilarity is too huge to be due to random occurrence, then a statistically significant $\mathrm{Z}$ score (standard deviations) is estimated. Thus $\mathrm{Z}$ scores and $\mathrm{P}$ values (statistical probabilities) are determined for every individual bin, these values clearly shows whether the change in crop cultivation in a particular bin is statistically clustered when matched with the change in adjacent bins. Besides they indicate whether the change in crop cultivation in a particular bin is statistically clustered, when matched with the change in neighbouring bins, in addition to the change across the whole domain. $\mathrm{Z}$ score lesser than 1.96 or greater than 1.96 shows the existence of a statistically significant cold or hot spot for change in wheat cultivation parameters (area, yield and production) at a significance level of $\mathrm{P}<0.05$. In general, clustering of values (hot spot) is more intense for a particular bin when it has a large $\mathrm{Z}$ score. Overall the neighbouring bins have both space and time components due to the existence of the data in cube structure. One prior time-step interval using (1 year) was used to define the temporal neighbours, similarly Queens Case Contiguity method was applied to delineate the neighbourhood size in space.

After getting the Z-scores from the Getis-Ord Gi* statistic, a Mann-Kendall statistic was performed to examine the existence of a statistically significant temporal trend within each bin's 17-year time series data (Mann, 1945; Kendall \& Gibbons, 1990). The existence of a trend can be examined using the most common simple linear regression technique. In general, a parametric statistical technique needs random samples that are independent and drawn from normally distributed populations (Granato et al. 2014). However when compared with a statistically drawn sample, wall-to wall geospatial data sets may or may not be fulfil these necessities (Schlagel \& Newton, 1996). Hence in such situations, the application of a non-parametric statistical test is further relevant. Slope is generally considered to be zero for the linear regression of time-ordered data with time (Mead et al. 2002), in Mann-Kendall test, which uses Kendall's rank order correlation test as a nonparametric test to time series data (Bradley, 1968).

Here, every individual bin with its data denotes its individual specific independent time series. Each time step was compare with one after other to determine the temporal trends in each bin. The result was considered as increasing trend $(+1)$, when the $\mathrm{Z}$-score of the succeeding time step was greater than the previous time step. Similarly the trend was considered to be decreasing (-1), when the Z-score in the succeeding time step was lesser than the previous time step. Thus for calculating the Mann-Kendall statistic for each bin, along with the corresponding trend in $\mathrm{Z}$ score and p-value, each pair of time steps were evaluated for a time period of 17 years. Whenever the predicted sum is zero, it indicates a no trend for the temporal change. Depending on the number of time periods and the variance for the values in the bin time series, the observed sum is compared to the expected sum (zero) to decide the statistical significance (P $<0.05)$ of the difference. Thus, on the basis of the Getis Ord $\mathrm{Gi}^{*}$ and Mann-Kendall statistics each bin is categorized based on their cluster and trend results. Hotspot analysis show the statistical significance regarding regions with high density of crop yield or area or production. . Hotspot analysis is useful for analyzing hotspots with high values, coldspots with low values, and for showing which spots have statistically significant patterns. On the other hand, Emerging Hot Spot Analysis identifies spatiotemporal trends in the data.

\subsection{Output maps}

Emerging Hot Spot Analysis tool available in the ArcGis 10.5 can categorize each and every one of the bin into one of seventeen distinctive categories. This classification covers different scenarios reflecting a range of configuration of spatiotemporal significance: one category of non-significance apart from eight cold spot and eight hot spot categories (Environmental Systems Research Institute (ESRI), 2016). Thus, presenting the results of the comprehensive information in cartographical map forms has the ability to focus the attention towards the most pertinent outputs for wheat crop cultivation. Thus all the categories of classifications with significant trends were displayed (Table 1). Outputs of the hot spot maps for each components (area, yield and production) of wheat cultivation in Indian sub-continent were evaluated against other prevailing data in order to interpret the relationship between each of the hot spot category to the changes in different components of wheat cultivation in India. 
Table 1 Classification system describing various categories of statistically significant hot/cold spots designating different spatial and temporal state.

\begin{tabular}{l}
\hline $\begin{array}{l}\text { Hot/cold sp } \\
\text { category name }\end{array}$ \\
\hline No Pattern Detected
\end{tabular}

\section{spot Definition}

Does not fall into any of the hot or cold spot patterns defined below.

New hot/cold

A location that is a statistically significant hot/cold spot only for the last time steps of the time series i.e., years 2014 and/or 2015

Consecutive hot/cold A location has never been a statistically significant hot/cold spot prior to the final hot/cold spot run and less than ninety percent of all bins are statistically significant hot/cold spots with a single uninterrupted run.

Intensifying hot/cold A location has been a statistically significant hot/cold spot for more than $90 \%$ of the time (15 of the 17 years), including the final year (2015). Additionally, the intensity of clustering of high counts in each time step is increasing.

Persistent hot/cold A location has been a statistically significant hot/cold spot for more than $90 \%$ of the time (15 of the 17 years), with no noticeable trend showing an increase or decrease in the intensity of clustering over time

Diminishing hot/cold A location that has been a statistically significant hot/cold spot for more than $90 \%$ of the time (15 of the 17 years). Furthermore, the degree of clustering of high counts in each time step is decreasing, or the most recent year (2015) is not hot/cold.

Sporadic hot/cold A location that is an on-again then off-again hot/cold spot. Less than $90 \%$ of the time (15 of the 17 years) have been statistically significant hot/cold spots.

Oscillating hot/cold A statistically significant hot/cold spot for the final time-step interval (2015) that has a history of also being a statistically significant cold/hot spot during a prior time step. Less than ninety percent of the time-step intervals have been statistically significant hot/cold spots.

Historical hot/cold
The most recent time period (2015) is not hot/cold, but at least ninety percent of the time-step intervals have been statistically significant hot/cold spots.

\section{RESULTS}

\subsection{Changes in Wheat crop Area, Production and Yield}

Within 1999 and 2015, wheat crop cultivation area has

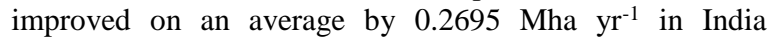
(Figure $2 \mathrm{a} \& \mathrm{~b}$ ), even though by and large the increase in rates improved during this time duration. India has improved its wheat production on an average of 2.107 MT $\mathrm{yr}^{-1}$ between 1999 and 2015 (Figure $2 \mathrm{a} \&$ b). From 1999 to

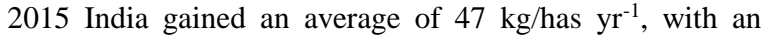
overall increase of about $47.14 \%$ in its wheat yield (productivity) (Figure $2 \mathrm{a} \& \mathrm{~b}$ ). The rate of increase in yield between consecutive years has consistently reduced in the recent years to the tune of -2 to +6 between 2010 and 2015, when compared to -7 to +7 between 1999 and 2003 (Figure $2 b)$.
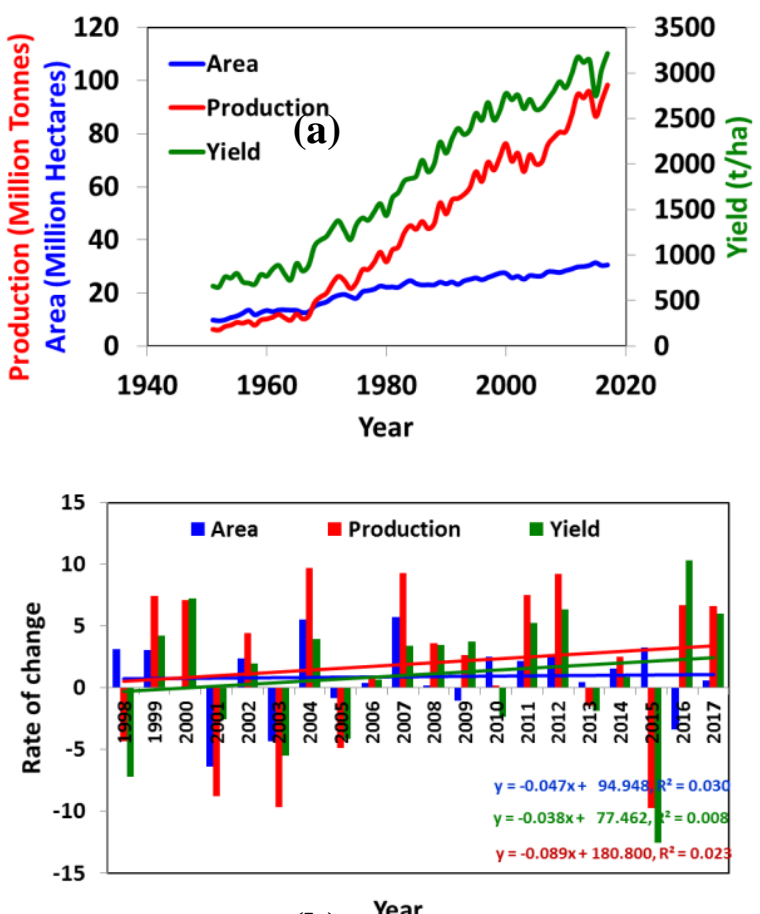

(b)

Figure 2 (a) Wheat crop Area, Production and yield in India (b) Rate of change in the Wheat crop Area, Production and yield in India

3.2 Need for analysing the spatio-temporal changes using Geo-statistics

For instance, Figure 3(a) displays crop yield in the state of Punjab in India during 1999 and 2015. In this local dimension, spatial patterns of increase are not easily visible to ascertain where to give importance for interventions or focus potential that require imminent improvement. At the region (Figure 3b) or country (Figure 3c) dimension, analysis through only visual examination alone does not provide distinct understanding on which sites to focus. Thus, there is a clear indication that the spatial association may be locally heterogeneous even though global spatial autocorrelation is observed. Hence there is a need for spatio-temporal analysis due to increasing availability of geographically disaggregated data as well as map files (e.g., shape files) 


\subsection{Effect of the domain size on emerging cold and hot} spot analysis

The numerical measure of an emerging cold and hot spot analysis is an important approach to logically comprehend for suitable explanation of outcomes. In general emerging cold and hot spot maps rely on the magnitude of the region under consideration for the analysis. For instance, Figure 4 illustrates the differences in the emerging hot spot maps when analysed with different analytical domains: a single state, Indo-Gangetic plain and all India. Output maps vary partly due to the fact that emerging hot spots analysis value for each and every bin are determined in relation to the 'over-all means', signifying the average change count over the entire region considered for the analysis.

\subsection{Effect of the neighbourhood size on emerging cold and hot spot analysis}

Outputs of the analysis are also affected by the size of the neighbourhood, otherwise the expanse by which every location is related with others. With the increase in the size of the neighbourhood, hot spots become bigger and less in number; analysis performed with smaller neighbourhood sizes could give better localized trends. In general, the extent of the analysis domain influences the neighbourhood size, hence there is a need
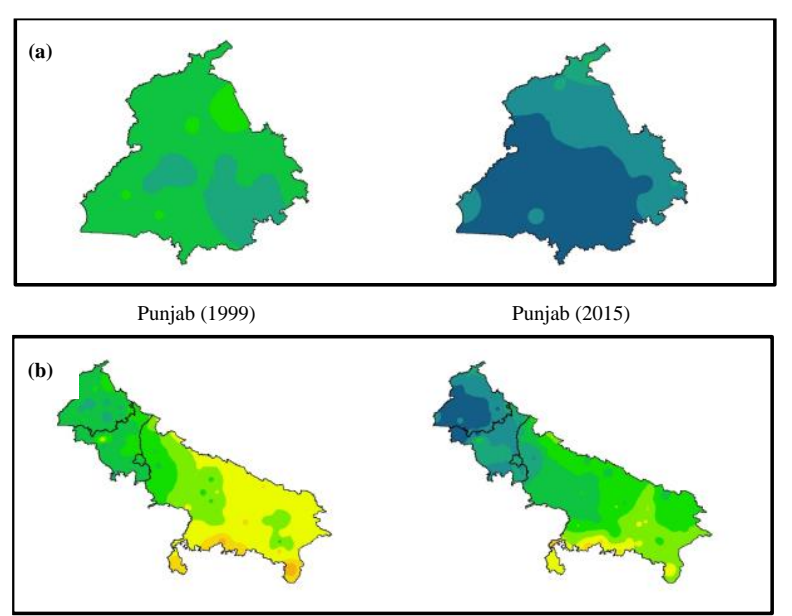

Indo Gangetic Plain (1999)

Indo Gangetic Plain (2015)

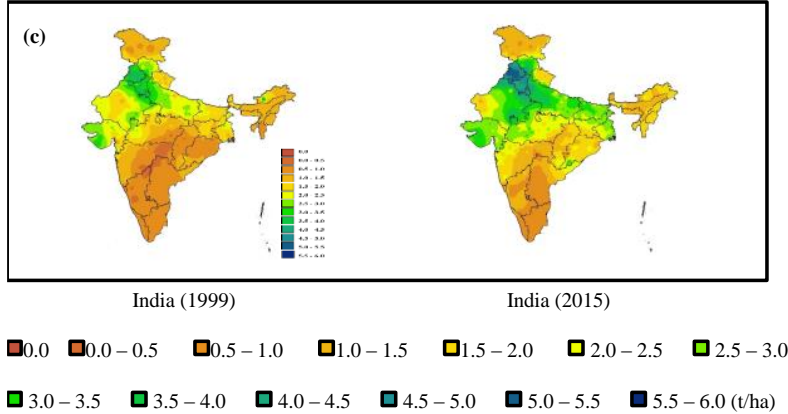

Figure 3. Change in wheat crop yield between the years

1999 and 2015 in India at three spatial scales: (a) local (Punjab district); (b) regional (Indo Gangetic plain); and (c) country (India). (a)
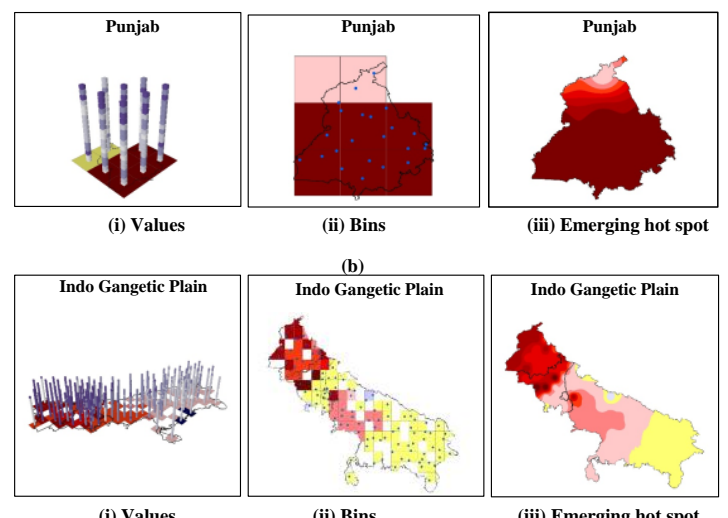

(c)

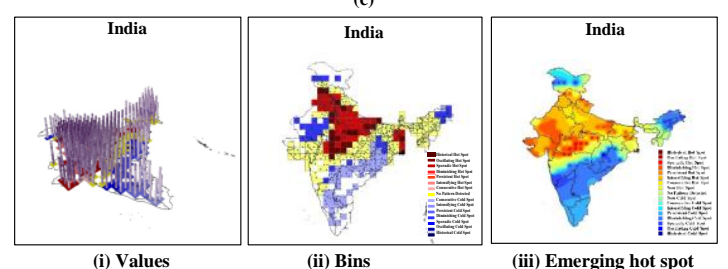

(i) Values

(ii) Bins

(iii) Emerging hot spot

Figure 4 Emerging cold and hot spot outputs for three different spatial domains of Wheat cultivation for yield local (Punjab state) (neighbourhood distance: $11.3 \mathrm{~km}$ ); (b) subnational (Indo Gangetic Plain) (neighbourhood distance $25 \mathrm{~km}$ ); and (c) national (neighbourhood distance $50 \mathrm{~km}$ ).

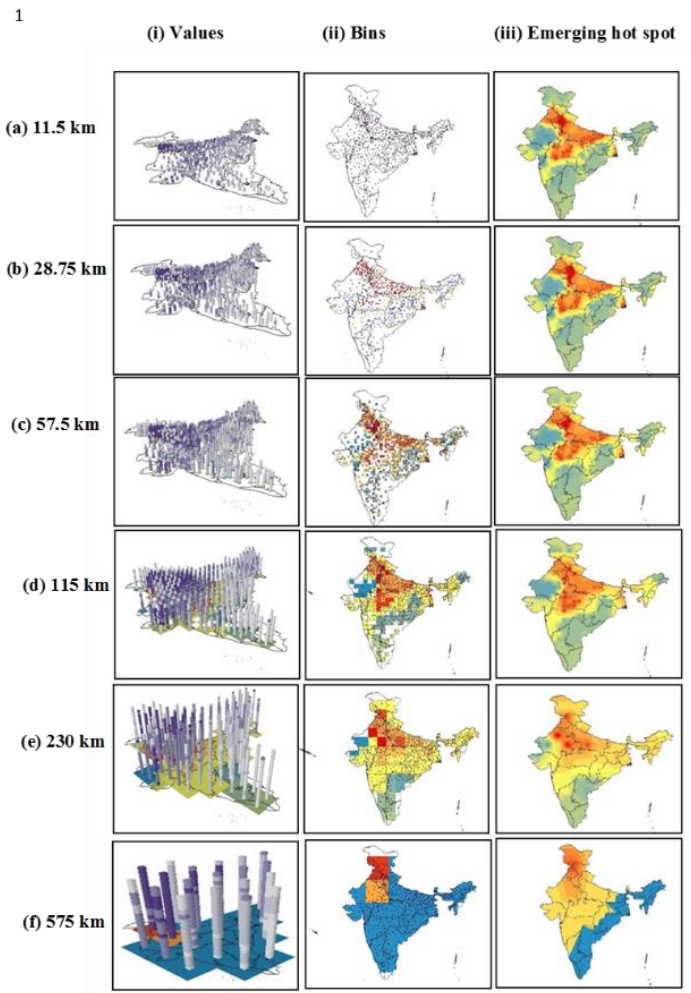

Figure 5. Hot and Cold spot results for wheat crop area, under six different neighbourhood distances: a) $11.5 \mathrm{~km}$; (b) $28.75 \mathrm{~km}$; (c) $57.5 \mathrm{~km}$; (d) $115 \mathrm{~km}$; (e) $230 \mathrm{~km}$; (f) 575 $\mathrm{km}$. With the increase in the neighbourhood distance, Hot and cold spots become larger and lesser; smaller neighbourhood distances detect trends confined to smaller areas. 
to utilize proper neighbourhood distances in this study Different extent of neighbourhood distances, and their effect on the output maps, is also given in Figure 5. In spite of the differences that come out from the analysis with different neighbourhood distances, the presence of emerging hot spots are usually consistent within the maps. In general as we have done for calculating the outputs in subsequent analysis, utilising an intermediate neighbourhood distance of $57.5 \mathrm{~km}$, in relation to the scale of analysis, brings out precise local hot spots, at the same time permit more common categories to appear.

\subsection{Spatio-temporal changes in Wheat Crop Area}

Aggregation of the original point data sets into space time cubes bins, which shows the data into its three-dimensional form with yearly time steps vertically stacked for each spatial location. The top most layer shows the data for the last time step, 2015. The results of the space time cube hot spot analysis gave corresponding z-scores to ach bin that indicates the intensity of hot and cold clusters. Each cluster in an area that is significantly different. From its surrounding Hot spot and cold spots results show areas where wheat is cultivated intensely and mildly, respectively than the surrounding neighbourhood areas. The cumulative $\mathrm{z}$-score results ignore the fluctuations between individual years, and focus on the overall clustering intensity for all years within the study period. These results are beneficial to depict the most consistent hot spots, but the following emerging hot spot analysis and three-dimensional hot spots are better for showing year-to-year changes.

Wheat acreage increased from $13 \%$ of the total cropped area in 1990-1991 to about $15 \%$ in 2009-2010. The cultivated area under wheat has increased $(12.5 \%)$ from approximately 21.50 million ha in 1999 to 31.5 million ha in 2015. Space time cube analysis clearly showed that the wheat acreage is mainly confined to the Indo-Gangetic Plains Region (Figure. 6), and three northern states, namely Uttar Pradesh $(35.53 \%)$, Punjab $(18.96 \%)$ and Haryana (13.39\%), account for $72 \%$ of India's total wheat acreage. In addition, Rajasthan $(8.31 \%)$ and Madhya Pradesh $(8.78$ $\%$ ) contribute a total acreage of $86 \%$. However, the above data do not reveal period- specific trends which enable us to compare recent and past growth trends. In India, during 2000/2001 and 2009/2010, states such as Chhattisgarh, Gujarat, Jharkhand, Madhya Pradesh, Maharashtra and Rajasthan underwent a major expansion in their wheat areas, whereas there was a marginal improvement in wheat areas in the major wheat-producing states (i.e., Haryana, Punjab and Uttar Pradesh). This points to a slight spatial shift in wheat cultivation from Haryana, Punjab and Uttar Pradesh to Madhya Pradesh, Rajasthan, Maharashtra and Gujarat.

Under emerging hot and cold spot analysis regions of maximum wheat cultivation (Figure 6), hot spot category (Figure 7), and persistent hotspot categories (Figure 8), is prominent within the Northern states of Uttarakhand and Uttar Pradesh, Punjab, Haryana indicating the increase in the clustering of gain in area under wheat crop there. Meanwhile, the diminishing hotspot is intensifying west over the state of Rajasthan and progressing towards western region of the Gujarat (Figure 8). These coincide with the Thar Desert regions of Rajasthan and the saline marshy regions of Gujarat (Figure 9). A new and significant cluster of consecutive cold spot signifying the area loss under wheat cultivation appears in states like Bihar, Chhattisgarh in the east, Karnataka in the south, Gujarat and Rajasthan in the west (Figure 8).

The three-dimensional hot spot analysis allows the entire stack of the space-time cube to be viewed. Areas that were marked new and intensifying in the emerging hot spot analysis can be examined through the complete annual range using this method. Figure 9 show a clear view of the northern most area comprising the Indo Gangetic plain as the identified hot spot region. Most locations became a hot spot within the last three-time steps and were only rarely hot spots in the earlier time steps. This provided verification that the change in preference to cultivate wheat has intensified only in the most recent time steps of the study period. Similarly, most of the southern, eastern, north eastern and south western regions are showing intensified cold spot in the recent past due to the non-preference for cultivating wheat in these regions.

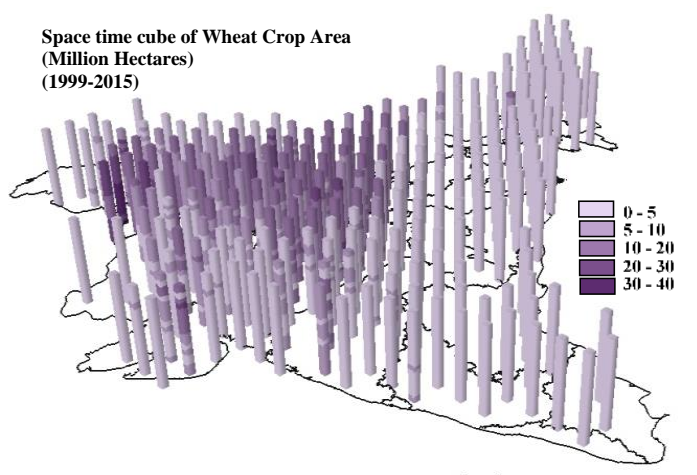

Figure 6. Space time cube of wheat crop area in India 1999-2015

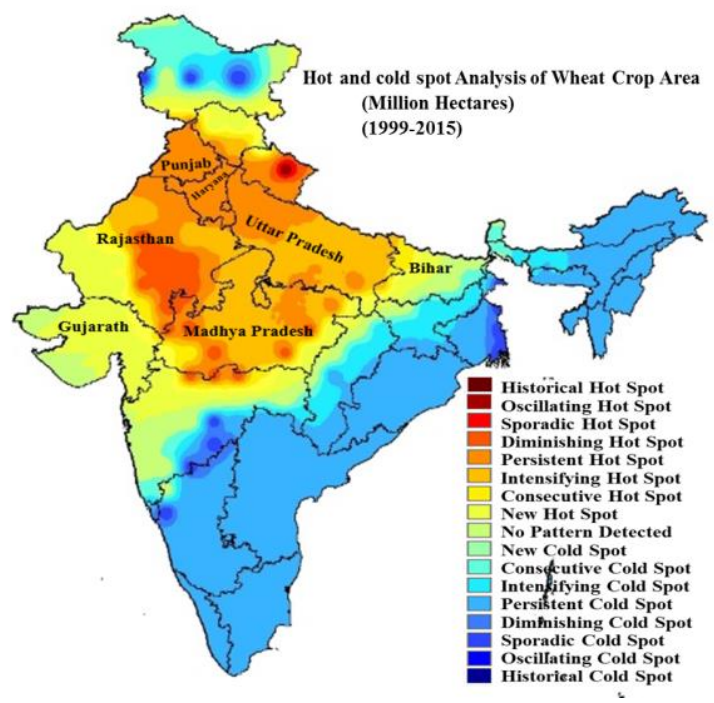

Figure 7 Emerging hot and cold spot analysis of wheat crop area 


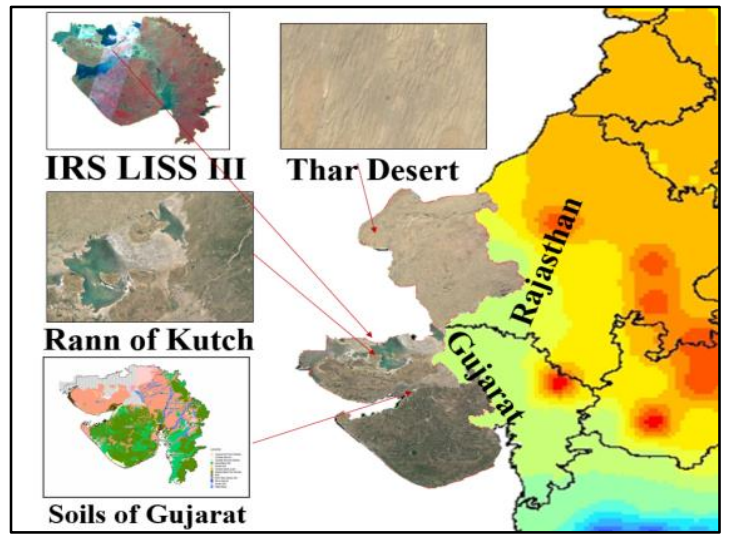

Figure 8. Diminishing hot spot coincide with the Thar Desert regions of Rajasthan and the saline marshy regions of Gujarat

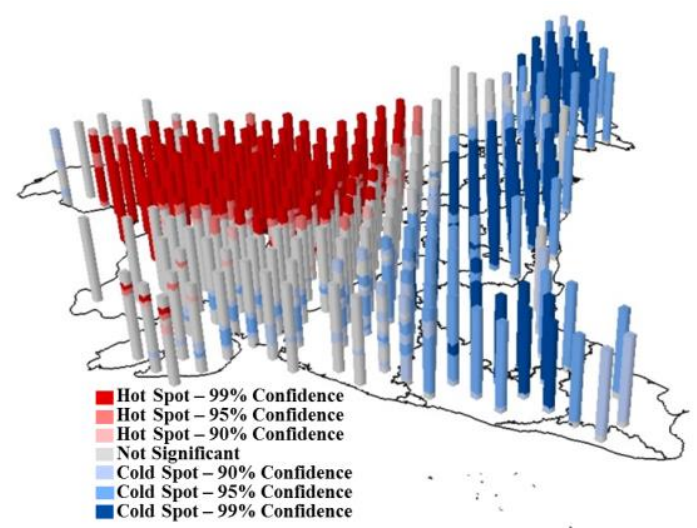

Figure 9. hot and cold spot map of change in wheat crop area

\subsection{Spatio - temporal changes in Wheat Crop Production}

In India, the major increase (about $70 \%$ ) in wheat production occurred within Indo-Gangetic plains (Figure 10). Emerging hot spot analysis (Figure 11) shows large areas of intensifying hot spots are existing in Uttar Pradesh, Haryana and Punjab. Unlike wheat crop area, wheat production lack diminishing hot spots over Indo - Gangetic plain. Persistent hot spots appear only in Punjab, Haryana, northern and north eastern Rajasthan, and eastern Uttar Pradesh. A Sporadic hot Spot pushes through Madhya Pradesh and South eastern parts of Rajasthan (Figure 11). These coincide with the river basins of Shipra, Kali Singh, Parba and Betwa (Figure 12). Consecutive hotspot appears in Uttara hand, Himachal Pradesh, central Uttar Pradesh. No change in the wheat production occurs in central parts of Rajasthan, parts of Bihar, Madhya Pradesh and Gujarat, northern parts of Jharkhand and north western regions of Chhattisgarh. No cold spot appears in the major wheat growing region located in the northern parts of India. Intensifying cold spots for wheat production in India occurs in the North Eastern states, southern parts of West Bengal, Jharkhand, Chhattisgarh and central Maharashtra (Figure 11). Persistent cold sport appear in whole of Odisha, Andhra Pradesh, Telangana, Karnataka and southern Maharashtra. New Cold Spot appear in the northern

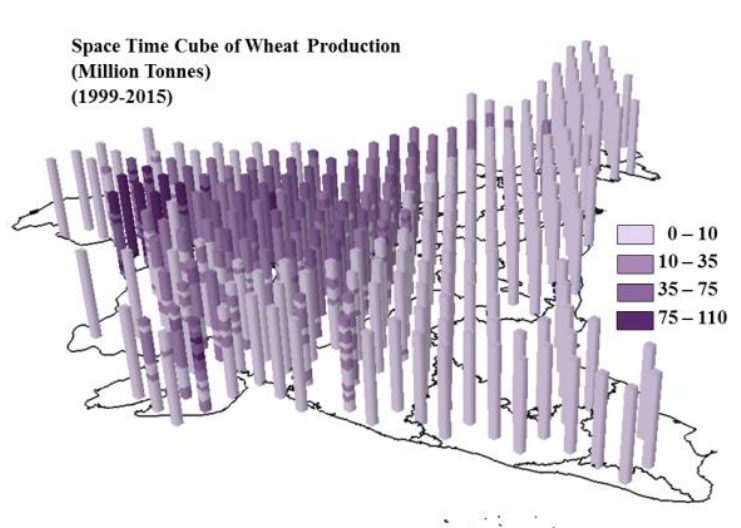

Figure 10 Space time cube of wheat crop production in India 1999-2015

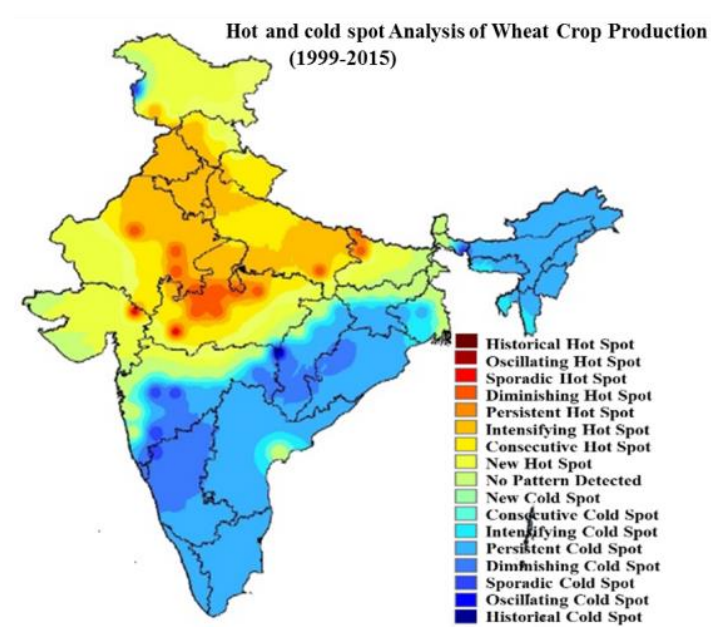

Figure 11 Emerging hot and cold spot analysis of wheat crop production

Gujarat and western Rajasthan. New cold spots also cover much of south Western Rajasthan, northern Gujarat encroaching into the northern parts of Maharashtra (Figure 12), where arid desert expansion is prevalent. Threedimensional Hot spot analysis (Figure 13) clearly showed major hotspots in the states of Punjab, Haryana and western UP. During 2015, Uttar Pradesh is the top most contributor of wheat production (25.22 MT), followed by Punjab (15.78 MT) and Madhya Pradesh (14.18 MT). It is interesting to note that the appearance hotspots in the major regions of Uttar Pradesh and North western regions of Rajasthan only during the recent past.

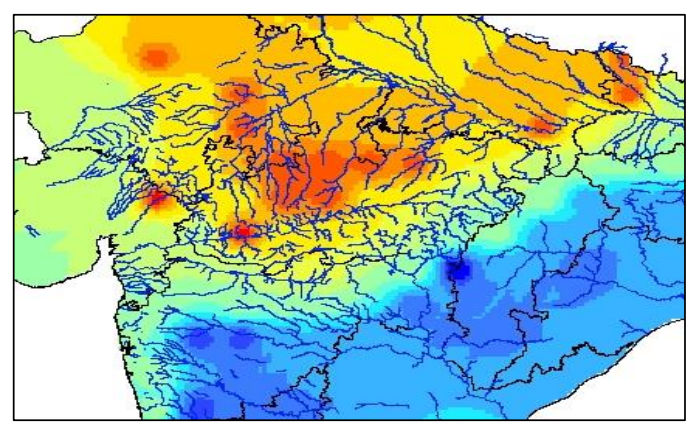

Figure 12. Wheat crop Production significant clusters of new and consecutive cold spot coincide with the river basins of Shipra, Kali Singh, Parba and Betwa 


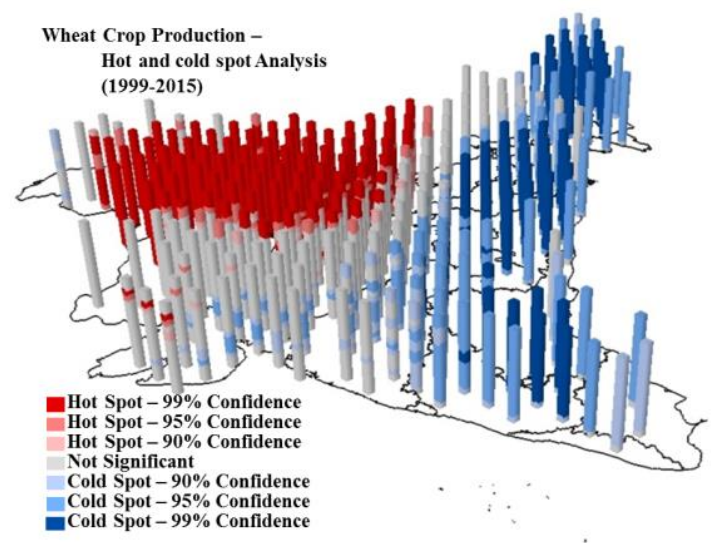

Figure 13. Hot and cold spot map of change in wheat crop Production

\subsection{Spatio - temporal changes in Wheat Crop Yield}

Like area and production, yield contains vast high and low yielding regions (Figure 14). Emerging hot and cold spot analysis of wheat crop yield (Figure 15) in India showed majority of the intensifying hot spots (Figure 15), present in the nation's northern part comprising the Indo-Gangetic plains (Figure 15). Unlike area and production, however, many more of the sporadic hot spots intersect along the western Gujarat, south eastern Rajasthan and southern Madhya Pradesh (Figure 15). Like area and production persistent cold spots are observed in the North Eastern states, southern regions of West Bengal, Jharkhand, Chhattisgarh, whole of Odisha,, Andhra Pradesh, Telangana, Karnataka and southern Maharashtra (Figure $15)$.

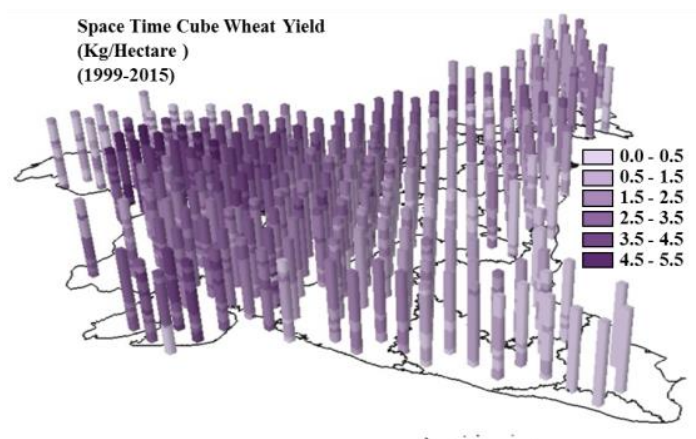

Figure 14. Space Time cube of wheat crop yield in India 1999-2015

Among the persistent hot spots of wheat yield in the northern India, New and consecutive hot spots of yield enhancement emanate from the metropolitan regions of Delhi, to the national Capital Region comprising 22 districts of the northern states of Haryana, Rajasthan and Uttar Pradesh which is a rural - urban region (Figure 16). Consecutive hot spots are also evident around city centres like National Capital Region (NCR) and Allahabad, where crop yield has reached its stagnation (Figure 16). The existence of consecutive hot spots in these sites implies less acceleration of yield improvement clustering around

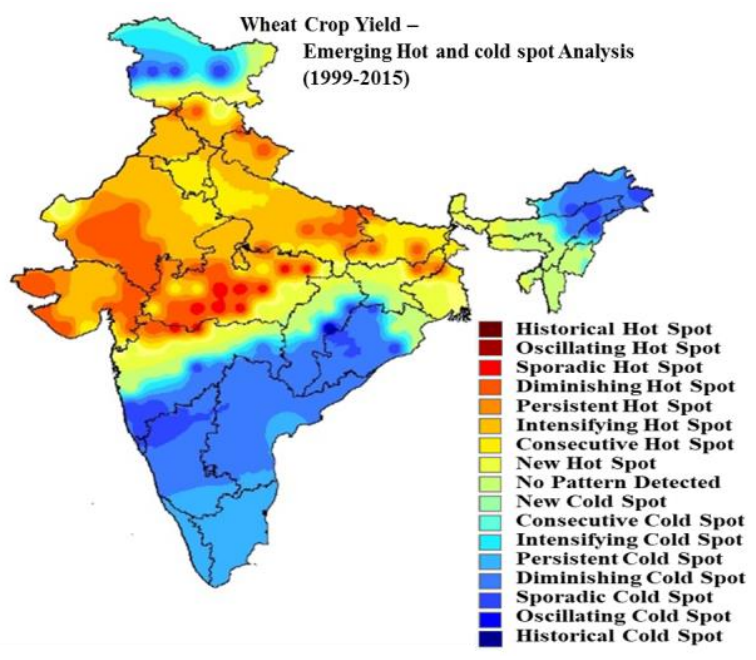

Figure 15. Emerging hot and cold spot analysis of wheat crop yield

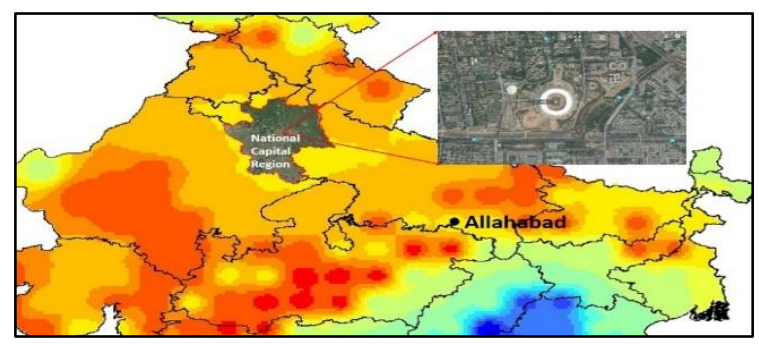

Figure 16. Consecutive hot spots apparent near city centres such as National Capital Region (NCR) and Allahabad

these, possibly as a consequence of transformation to new settlements. Three-dimensional analysis of the hot and cold spot showed majority of the hot spots are present in the northern part of India comprising the majority of the wheat growing regions of India (Figure 17). Large part of the eastern UP, western Bihar, Rajasthan and Gujarat are showing hotspots only during the recent few years. On the other hand regions of Maharashtra, Karnataka and Chhattisgarh are showing cold spots.

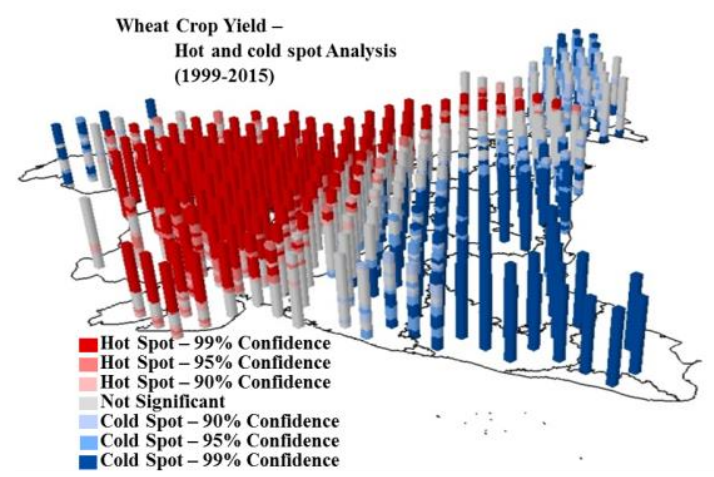

Figure 17. Three dimensional changes in Hot and cold spot map of wheat crop yield

\section{DISCUSSION}

Wheat is one of the staple foods in India. Wheat is an important crop in terms of both production and consumption. India almost exclusively raises winter wheat. Wheat is mainly grown in the Rabi season (OctoberDecember to March-May) along with barley, lentils, peas, 
mustard and potatoes. The planting of winter wheat begins about 1 st of October and runs through to the end of December. Wheat will usually begin to head in January, with the harvest following in March, April and May. Wheat acreage increased from $13 \%$ of the total cropped area in 1990-1991 to about $12 \%$ in 2014-2015. Wheat production is mainly confined to the Indo-Gangetic Plains Region, and three northern states, namely Uttar Pradesh (35.53\%), Punjab $(18.96 \%)$ and Haryana (13.39\%), supply $72 \%$ of India's total wheat output. In addition, Rajasthan $(8.31 \%)$ and Madhya Pradesh $(8.78 \%)$ contribute a total output of $86 \%$. We utilised spatio-temporal analysis at the national level for Indian sub-continent over 17 years, however the methodology is extendable to any temporal or spatial domain having greater than $\sim 10$ time steps. For site specific analysis, this GIS based technique may provide great benefit when compared to observing the data in its available form (Diacono et al. 2012). There is unavoidably a component of biasness in selecting a suitable value for neighbourhood distance; but according to Atkinson and Unwin (2002) unbiased decision on the basis of a multiple density surfaces, as adopted in this study is a beneficial method to determine the suitable neighbourhood size. Spatio-temporal investigations using Emerging Hot Spot Analysis is more precise for assessing the trends happening over larger dimensions under meagre resources and constrained time. Similarly emerging hot and cold spot analysis may be helpful for prioritization, inspection and implementation of efforts to manage particular fronts of recent or accelerated damage (Harrris et al. 2017).

In this study we demonstrated the spatio-temporal analysis of wheat cultivation by applying the Emerging Cold and Hot Spot Analysis to evaluate statistically significant clusters for wheat crop cultivation in terms of area, production and yield in India. Unlike traditional analytical modelling methods, our approach and methodology can be executed transiently and needs least information on the essential factors of enhancement of wheat crop cultivation (Chen et al. 2017). Nevertheless outcomes of the analysis can give better insight on probable impending projections and sites for enhancement of wheat cultivation (Ceglar et al. 2017). Results from the spatio-temporal analysis using the emerging hotspot analysis are well correlated with the actual observed facts. The presence of consecutive hot spots for yield in the northern India suggests less acceleration of yield improvement occurring there, similar observations on changes in wheat yield was made by Tripathi and Mishra, 2017; Sendhil et al., 2018 and Asseng et al., 2017), probably as a result of transformation to new settlements as a consequence of an intensifying rural complex due to NCR's fast increasing population (Statistical Abstracts of Delhi (SAD), 2014). Similarly the new cold spot appearance in the northern Gujarat and western Rajasthan for wheat crop area, coincides with the saline water intrusions and the presence of arid desert (Roy et al. 2016) respectively. Our result on cold spot for wheat yield increase in southern India is consistent with the observation that high temperatures already limit wheat production in southern India (Trethowan et al., 2018). Similarly studies have shown that India will not be able to meet the growing demand for wheat in upcoming years due to increase in population (Tripathi and Mishra, 2017) and climate change (Asseng et al., 2017).

Every spatial clustering methods, irrespective of their theoretical specification, statistical underpinning, or mathematical background, have constrains on computational effort, sensitivity and accuracy needed for classifying different categories (Hamada et al. 2015). Due to this, a key challenge in technique (s) is limiting which approach will give the complete significant understandings for a specific context or issue (Grubesic et al. 2014). Hence appropriate data layers are particularly necessary to decipher the outputs, same is the case with understanding the truthfulness of the actual data product considered for the statistical results (Hamada et al. 2015). In this study factual data on wheat crop area, production and yield available with government of India is used. These data are collected by the government agencies based on the experiments and observations conducted by the government of India (Sinha, 2004).

Structure of the approach explained in this study reveals the additional logical importance provided by crop monitoring data having better temporal regularity, or resolution (Harris et al. 2017). Although in this study we have used a government data to explain the spatio-temporal assessment using emerging hotspot analysis approach all over India, with comparatively better characterised crop cultivation parameters, similarly data with space and time element can be assessed with this method (ESRI, 2016). Based on the requirement for a particular research problem, analogous analysis could be made on other agricultural data, meteorological weather data, remote sensing data products, such as NDVI, Chlorophyll, forest loss (Harris et al. 2017) etc. Similarly for continuous variables data could be combined with numerical values instead of count; for instance, in applications characterising the sites for crop management to reduce greenhouse gas emissions from paddy fields, instead of area of cultivation, bin values could reveal the actual change occurring inside a bin during a particular year. In the present study, years and point locations could be similar to those for the crop cultivation data as in Ray et al. (2013), however combined spatio and temporal changes in terms of emerging hot and cold spot maps produced from the present approach would vary depending on the aggregation technique, specifically in sites in which a considerable difference in wheat cultivation (Teixeira et al. 2014) is observed. Within the emerging hot spot map of area, yield and production of wheat crop cultivation produced in this study, the quantity of change within a bin determines the analysis, than the existence or extinction of a difference.

The largest domain on which this type of analysis could be performed was actually determined by the computing strength of the machine in such analyses were made (Harris et al. 2017). Current advances in parallel processing and cloud computing can eliminate such bottlenecks, so that multifaceted individual data assessment at small and large expanses is feasible in addition sensitivity of outputs to diverse factors can also be evaluated (Ceglar et al. 2017). We have provided a technique for dynamically and quickly evaluating the combined spatial and temporal changes in wheat crop cultivation, and the method could be assessed for fresh temporal frames with extra time steps added further. Thus going further, investigation of crop cultivation data by the present approach could assist governments, resource groups, environmental managers, and agricultural officers who can gain quick understanding on where to emphasise on crop management and improvement interventions for wheat cultivation for a particular region and time periods of interest (Zhang et al. 2017). Decision makers challenged with scrutinising anticipated wheat 
cultivation improvement, commodity supply chain sourcing through various stakeholders or policy decisions may profit though the provision of maps which are simple to understand, nevertheless substantiated with strong statistical analysis (Basso et al. 2014). National and subnational government authorities in wheat crop improvement programs could consider the emerging hot and cold spot approach beneficial for apprising their action plans, national and international strategies.

\section{CONCLUSION AND FUTURE RESEARCH}

Access to crop cultivation data with reduced delay in time is making enormous spurts of complex and factual data available to the agricultural research community. Solution to make use of these agricultural data in crop improvement program could enable the decision makers to quickly analyse and understand them, use the factual data into executable discernments that could help in appropriate and proper conversant management decisions. Technological and computational improvement in both data analysis and monitoring could permit the approach described in this study to be used in unique manner to permit better understanding and superior management of multifaceted agricultural production systems.

\section{ACKNOWLEDGMENTS}

Present study is a part of the ongoing institutional project (No. CRSCIARISIL2014028260) on "Risk Assessment \& Management of Hydro - climatic Hazards on Natural Resource Degradation \& Agricultural Sustainability" funded by ICAR-IARI.

\section{REFERENCES}

Acharya, S., Chand, P., Birthal, S., \& Negi, D. 2012. Market Integration and Price Transmission in India: A Case of Rice and Wheat with Special Reference to the World Food Crisis of 2007/08. Food and Agriculture Organization. Rome.

Asseng, S., Cammarano, D., Basso, B., Chung, U., Alderman, P.D., Sonder, K., Reynolds, M. and Lobell, D.B., 2017. Hot spots of wheat yield decline with rising temperatures. Global change biology, 23(6), pp.2464-2472.

Atkinson, P.J., \& Unwin, D.J. 2002. Density and local attribute estimation of an infectious disease using MapInfo. Computers \& geosciences, 28(9): pp.1095-1105.

Basso, B., Cammarano, D., \& Carfagna, E. 2013, July. Review of crop yield forecasting methods and early warning systems. In Proceedings of the First Meeting of the Scientific Advisory Committee of the Global Strategy to Improve Agricultural and Rural Statistics, FAO Headquarters, Rome, Italy (pp. 18-19).

Bradley, E.F. 1968. A micrometeorological study of velocity profiles and surface drag in the region modified by a change in surface roughness. Quarterly Journal of the Royal Meteorological Society, 94(401): pp.361-379.

Ceglar, A., Turco, M., Toreti, A., \& Doblas-Reyes, F.J. 2017. Linking crop yield anomalies to large-scale atmospheric circulation in Europe. Agricultural and Forest Meteorology, 240, pp.35-45.
Chen, Y., Zhang, Z., Tao, F., Wang, P., \& Wei, X. 2017. Spatio-temporal patterns of winter wheat yield potential and yield gap during the past three decades in North China. Field Crops Research, 206: pp.11-20.

Diacono, M., Castrignanò, A., Troccoli, A., De Benedetto, D., Basso, B., \& Rubino, P. 2012. Spatial and temporal variability of wheat grain yield and quality in a Mediterranean environment: A multivariate geostatistical approach. Field Crops Research, 131: pp.49-62.

Environmental Systems Research Institute (ESRI). 2016. 'How Emerging Hot Spot Analysis Works' (http://desktop.arcgis.com/en/arcmap/ 10.3/tools/spacetimepattern-mining-toolbox/learnmoreemerging.htm)

(Accessed: 28 March 2017)

Food and Agriculture Organization (FAO). 2017. The future Trends of food and challenges ISBN 978-92-5109551-5. 163Pp. http://www.fao.org/3/a-i6583e.pdf

Food and Agriculture Organization of the United Nations (FAOSTAT), 2017. FAO Statistics Division 2017. Available at http://faostat.fao.org

Getis, A., \& Ord, J.K. 1992. The analysis of spatial association by use of distance statistics. Geographical analysis, 24(3): pp.189-206.

Gilliham, M., Able, J.A., \& Roy, S.J. 2017. Translating knowledge about abiotic stress tolerance to breeding programmes. The Plant Journal, 90(5): pp.898-917.

Godfray, H.C.J., \& Garnett, T. 2014. Food security and sustainable intensification. Phil. Trans. R. Soc. B, 369(1639): p.20120273.

Granato, D., de Araújo Calado, V.M., \& Jarvis, B. 2014. Observations on the use of statistical methods in food science and technology. Food Research International, 55: pp.137-149.

Grubesic, T.H., Wei, R., \& Murray, A.T. 2014. Spatial clustering overview and comparison: Accuracy, sensitivity, and computational expense. Annals of the Association of American Geographers, 104(6), pp.1134-1156.

Hamada, Y., Ssegane, H., \& Negri, M.C. 2015. Mapping intra-field yield variation using high resolution satellite imagery to integrate bioenergy and environmental stewardship in an agricultural watershed. Remote Sensing, 7(8), pp.9753-9768.

Harris, N.L., Goldman, E., Gabris, C., Nordling, J., Minnemeyer, S., Ansari, S., Lippmann, M., Bennett, L., Raad, M., Hansen, M., \& Potapov, P. 2017. Using spatial statistics to identify emerging hot spots of forest loss. Environmental Research Letters, 12(2), p.024012.

Kang Y, Cho N and Son S (2018) Spatiotemporal characteristics of elderly population's traffic accidents in Seoul using space-time cube and space-time kernel density estimation. PLoS One13(5): e0196845. doi: 10.1371/journal.pone.0196845. eCollection 2018.

Kannan, E. and Sundaram, S., 2011. Analysis of trends in India's Agricultural Growth. Institute for Social and Economic Change.25 Pp.

Kendall, M.G., \& Gibbons, J.D. 1990. Rank correlation methods, trans. JD Gibbons, 5th edn edition (London, Edward Arnold). 
Kogan, F., Kussul, N., Adamenko, T., Skakun, S., Kravchenko, O., Kryvobok, O., Shelestov, A., Kolotii, A., Kussul, O., \& Lavrenyuk, A. 2013. Winter wheat yield forecasting in Ukraine based on Earth observation, meteorological data and biophysical models. International Journal of Applied Earth Observation and Geoinformation, 23, pp.192-203.

Lobell, D.B., Sibley, A., \& Ortiz-Monasterio, J.I. 2012. Extreme heat effects on wheat senescence in India. Nature Climate Change, 2(3), pp.186-189.

Mann, H.B. 1945. Nonparametric tests against trend. Econometrica: Journal of the Econometric Society, pp.245259.

Mead, R., Curnow, R.N., \& Hasted, A.M. 2002. Statistical methods in agriculture and experimental biology (Vol. 55). CRC Press.

Monfreda, C., Ramankutty, N., \& Foley, J.A. 2008. Farming the planet: 2. Geographic distribution of crop areas, yields, physiological types, and net primary production in the year 2000. Global biogeochemical cycles, 22(1).

National Food Security Mission (NFSM), 2014. National Food Security Mission, Progress report, Wheat 2013-14, http://nfsm.gov.in/progressReport.aspx\#

Ord, J.K., \& Getis, A. 1995. Local spatial autocorrelation statistics: distributional issues and an application. Geographical analysis, 27(4), pp.286-306.

Organisation for Economic Co-operation and Development (OECD), 2017. Crop production (indicator). doi: 10.1787/49a4e677-en (Accessed on 28 April 2017)

Priya, S., \& Shibasaki, R. 2001. National spatial crop yield simulation using GIS-based crop production model. Ecological Modelling, 136(2), pp.113-129.

Ramankutty, N., Evan, A.T., Monfreda, C., \& Foley, J.A. 2008. Farming the planet: 1. Geographic distribution of global agricultural lands in the year 2000. Global Biogeochemical Cycles, 22(1).

Ray, D.K., Mueller, N.D., West, P.C., \& Foley, J.A. 2013. Yield trends are insufficient to double global crop production by 2050 . PloS one, 8(6), p.e66428.

Ray, D.K., Ramankutty, N., Mueller, N.D., West, P.C., \& Foley, J.A. 2012. Recent patterns of crop yield growth and stagnation. Nature communications, 3, p.1293.

Roy, P.D., \& Singhvi, A.K. 2016. Climate variation in the Thar Desert since the Last Glacial Maximum and evaluation of the Indian Monsoon. TIP Revista Especializada en Ciencias Químico-Biológicas, 19(1), pp.32-44.

Schlagel, J.D., \& Newton, C.M. 1996. A GIS-based statistical method to analyze spatial change.
Photogrammetric engineering and remote sensing, 62(7), pp.839-844.

Sendhil, R., Jha, A., Kumar, A. and Singh, S., 2018. Extent of vulnerability in wheat producing agro-ecologies of India: Tracking from indicators of cross-section and multidimension data. Ecological Indicators, 89, pp.771-780.

Shiferaw, B., Smale, M., Braun, H.J., Duveiller, E., Reynolds, M., \& Muricho, G. 2013. Crops that feed the world 10. Past successes and future challenges to the role played by wheat in global food security. Food Security, 5(3), pp.291-317.

Sinha, S. 2004. Agriculture insurance in India: scope for participation of private insurers. Economic and Political Weekly, pp.2605-2612.

Statistical Abstracts of Delhi (SAD), 2014. Government of NCT of Delhi http://www.delhi.gov.in/wps/wcm/connect/f508bc8046667 b0e9cf6bcf5a4ed47e7/Stattistical+Abstract+of+Delhi+2014 .pdf?MOD=AJPERES\&lmod=66436406\&CACHEID $=$ f508 bc8046667b0e9cf6bcf5a4ed47e7

Teixeira, E.I., Fischer, G., van Velthuizen, H., Walter, C., \& Ewert, F. 2013. Global hot-spots of heat stress on agricultural crops due to climate change. Agricultural and Forest Meteorology, 170, pp.206-215.

The International Wheat Yield Partnership (IWYP), 2016. Annual Report, $2016 \quad$ http://iwyp.org/wpcontent/uploads/sites/34/2016/09/IWYP-YR1-Annual$\underline{\text { Report-Published.pdf }}$

Tilman, D., Balzer, C., Hill, J., \& Befort, B.L. 2011. Global food demand and the sustainable intensification of agriculture. Proceedings of the National Academy of Sciences, 108(50): pp.20260-20264.

Trethowan, R., Chatrath, R., Tiwari, R., Kumar, S., Saharan, M.S., Bains, N., Sohu, V.S., Srivastava, P., Sharma, A., De, N. and Prakash, S., 2018. An analysis of wheat yield and adaptation in India. Field Crops Research, 219, pp.192-213.

Tripathi, A., and Mishra, A., 2017. The wheat sector in India: Production, policies and food security. Chapter in S. Gomez y Paloma et al. (eds.), The Eurasian Wheat Belt and Food Security. Springer, ISBN 978-3-319-33239-0. Pages 275 - 296. DOI http://dx.doi.org/10.1007/978-3-319-33239$\underline{0 \quad 17}$

Wheat Initiative, 2011. Wheat Initiative at a Glance http://www.wheatinitiative.org/sites/default/files/attached_f ile/wheatinitiative_visiondocument.pdf.

Zhang, X., Obringer, R., Wei, C., Chen, N., \& Niyogi, D. 2017. Droughts in India from 1981 to 2013 and Implications to Wheat Production. Scientific Reports, 7, p.44552. 